\title{
Brutalitas Kapitalisme Di Indonesia
}

Shohibul Anshor Siregar

Indonesia sebagai salah satu Negara yang sedang membangun di kawasan Asia Tenggara pernah dituduh menerapkan apa yang disebut ersatzs capitalism atau pseudo capitalism (kapitalisme malu-malu).

Dalam bukunya The Rise of Ersatz Capitalism in South-East Asia(1988), Kunio Yoshihara menganggap pertumbuhan ekonomi yang dihasilkan tidak efisien, dan ini berdampak pada kemampuan pembangunan ekonomi di masa depan. Kunio Yoshihara adalah salah seorang penganjur yang kuat untuk penerapan kapiltalisme secara total dengan tiga resep: pertama, menanggulangi keterbelakangan teknologi; kedua, memperbaiki kualitas intervensi pemerintah; ketiga, menghapus diskriminasi terhadap orang-orang keturunan Cina.

Ketiga faktor itu dianggapnya dapat merombak watak pembangunan yang tidak efisien untuk berubah menjadi kapitalisme yang tak berbeda dengan di Jepang dan dunia Barat pada umumnya. Dengan mudah ia berkata, bahwa hambatan sistem sosial dan politik harus dihapus agar kapitalisme yang dinamis dapat tumbuh.

Kelihatannya nasehat Kunio Yoshihara itulah yang kini diikuti oleh Indonesia. Hasilnya sudah semakin jelas, antara lain bentuk nyata pengangkangan terhadap amanat konstitusi dan munculnya pertumbuhan eksklusif di tengah kemiskinan massal dan rakyat miskin dipaksa berkompetisi untuk memperebutkan hak-hak normatif saja semisal pendidikan, kesehatan dan mendapatkan kebutuhan hidup sehari-hari yang sesungguhnya dijamin dan menjadi tanggungjawab negara.

\section{Keterbelakangan Teknologi}

Sejarah pembangunan di Indonesia memiliki keberangsuran untuk pada akhirnya menjadi sangat neoliberal, menjauh dari watak asli yang digariskan oleh konstitusi, yakni ekonomi berbasis kekeluargaan (kebersamaan) dengan wadah koperasi sebagai sokoguru. Gagasan-gagasan globalisasi malah semakin memastikan ketersingkiran rakyat mayoritas, dan tak beruntungnya, Indonesia berada pada posisi at the point of no return untuk program yang dikendalikan oleh Negara-negara besar itu. Ini tak lain dari brutalitas kapitalisme yang akan memaksa mayoritas rakyat Indonesia akan kembali menjadi budak di negeri sendiri.

Dengan alasan keterbelakangan teknologi dan modal, Indonesia menjadi Negara yang sangat tergantung kepada asing. Ini sesuatu yang sangat berbeda dengan ungkapan go to hell with your aids yang diucapkan Bung Karno dalam menilai neo-imperialisme dan neo-kolonialisme yang dibalut halus oleh kerjasama-kerjasama bilateral dan unilateral terkait teknologi dan permodalan.

Sebagai interpretator harismatik dan paling berpengaruh untuk konstitusi Indonesia, ditambah dengan otoritasnya sebagai Presiden, Soekarno tak hanya menjelaskan tata dunia yang harus dibangun berbasis keadilan dan menawarkan Pancasila kepada dunia melalui Majelis Umum PBB dalam sebuah kesempatan penting (Sidang Majelis Umum PBB Ke XV). la juga sangat aktif memerangi gagasan dan tindak-tanduk neo- 
imperialisme dan neo-kolonialisme sebagaimana tercakup dalam "jimat" Trisaktinya (berdaulat politik, berdaulat ekonomi, dan berdaulat budaya). Ada benang merah antara pidatonya To Build The World A New di Majelis Umum PBB dengan buku yang ditulisnya berjudul Sarinah, dan inisiatifnya membangun Masjid Istiqlal, Stadion Gelora Utama Bung Karno, Tugu Monas, Hotel Indonesia, dan sebuah pusat perbelanjaan dengan konsep murah-meriah-berkualitas untuk bangsa, yakni Sarinah, yang kesemuanya menunjukkan rujukan pada gagasan trisakti.

Bung Karno juga menunjukkan tidak asal bicara tentang keadilan dalam tata dunia. Selain tindakan-tindakannya yang mendunia, ia juga melakukan kebijakan yang mengubah strutur ekonomi dan keekonomian bangsa antara lain dengan pembentukan ekonomi benteng, sebuah program yang mengadvokasi dan memberi akses serta permodalan bagi kalangan pribumi agar mampu tumbuh menjadi pengusaha yang kuat dan tangguh mengiringi kemerdekaan Indonesia sesuai proklamasi dan jabaran trisakti. Indonesia terjajah selama sekian lama menerapkan tiga hukum diskriminatif (hukum khusus untuk Eropa, khusus untuk Timur Asing dan hukum untuk priboemi) yang menyebabkan Indonesia menghadapi ketidak-adilan ekonomi secara struktural. Semua gagasan dan cita-cita besar Bung Karno kandas atas nama pembangunan di tangan rezim yang silih berganti.

Akhirnya kini watak (baru) pemerintahan Indonesia ialah kompradorisasi yang menyahuti penuh antusias logika pertumbuhan yang didasarkan pada teori besar trickle down effect. Teori ini terbukti menyesatkan dunia dan bertanggung-jawab atas ketimpangan struktural yang parah dan berlangsung secara kontinum (tanpa batas), baik di seluruh belahan dunia maupun internal semua negara.

Brutalitas kapitalisme muncul di Indonesia sejak awal yang menyebabkan kekayaan sumberdaya alam tidak menjadi kebahagiaan bagi rakyat. Koperasi ditelantarkan dan serpihan-serpihan yang dianggap menjadi jatah pribumi diatur sedemikian rupa dengan transaksi-transaksi gelap antara wakil-wakil kapitalis dengan tokoh-tokoh politik nasional di lembaga perwakilan untuk memastikan Negara sebagai komoditi bagi pemodal. Gejala ini menguat tanpa terkendali setelah kekuatan-kekuatan politik dunia berhasil melegitimasi liberalisi demokrasi di Indonesia.

Negara manakah di dunia ini yang tak mengeluh tentang teknologi dan modal? Jika Negara itu tak menjadi budak bagi yang lain, itu artinya ada inisiatif dan iktikad yang kuat untuk membangun kemandirian. Pengalaman panjang di bawah kekuasaan VOC sebetulnya lebih dari cukup untuk menyadarkan Indonesia bahwa pembangunan bukanlah keberhasilan membawa kapitalis dunia menjadi raja yang menentukan arah perjalanan Indonesia dalam ketergantungan.

Keseriusan dan kejujuran Negara sangat ditunggu untuk merombak struktur ekonomi dengan pilihan investasi yang tepat untuk memberdayakan rakyat. Tiga puluh tahun lalu Indonesia adalah sebuah raksasa ekonomi dan Cina beserta India berada jauh di bawah grade kemampuan Indonesia. Tetapi kini Vietnam yang babak-belur dalam perang melawan hegemoni Amerika kini sudah menyamai Indonesia dalam banyak hal. Belum lama ini Wapres JK menyebut fakta kesenjangan structural, tetapi tidak ada bahasa ketersinggungan yang akan ditindak-lanjuti dengan kebijakan menghadapi 
fakta tak terbantahkan bahwa hanya $1 \%$ (satu persen) warga Negara Indonesia yang secara kukuh menguasai asset dan perputaran ekonomi sebesar $50 \%$ (lima puluh persen).

Intervensi pemerintah

Dalam catatan sejarah tidak dapat dipungkiri mutlak pentingnya peran dan dukungan serta keterlibatan penuh dari militer dalam kepolitikan otoritarianisme-birokratik selama Orde Baru. Rezim itu pada dasarnya adalah rezim militeristik yang tidak bersedia disebut sesuai sifatnya itu. Memang, militer, tak diragukan lagi, adalah salah satu kelompok terpenting pada masa itu dan pula yang paling memenuhi persyaratan dan kapabilitas untuk memikul beban berat yang. mesti diemban oleh Orde Baru dengan tekadnya untuk mensejahterakan melalui pembangunan sambil mencaci Orde Lama dengan predikat komunistis sejalan dengan peta global perang dingin dunia yang terpilah. Tetapi militer tidak hadir tiba-tiba saat Soeharto naik tahta. Jenderal $\mathrm{AH}$ Nasution banyak bercerita tentang gagasan Dwi Fungsi ABRI. Itulah raison d'etre (alasan pembenar) keterlihatan langsung militer dalam politik.

Menyadari militer sebagai salah satu kekuatan politik yang tangguh sejak Demokrasi Terpimpin (guided democracy) bikinan Soekarno untuk memasilitasi angan-angannya menjadi semacam "raja" baru Indonesia merdeka, peran militer dalam birokrasi bahkan sudah dirintis sejak awal sebagaimana diterangkan Sundhaussen (1982) dalam The Road to Power: Indonesian Military Politics, 1945-1967.

Yahya A.Muhaimin dalam kuliahnya (Militer di Negara Berkembang) di Fisipol-UGM, tanggal 2 dan 9 Mei 1993 mencatat banyak hal yang kemudian dikenali menjadi faktor kendala dengan menitik-beratkan profesionalisme militer yang secara inheren terdapat semacam technical inability to administrate, di samping sebenarnya juga tak dapat dipungkiri lack of legitimacy to govern. Alasannya sederhana, bahwa kehidupan sosial dan politik di luar kehidupan milter itu jauh lebih kompleks daripada kehidupan militer itu sendiri, meski kaum militer selalu merasa dirinya suprematif dan serba mampu serta serba bisa. Akibatnya kelak dapat dirasakan bahwa begitu besar penelantaran dimensi-dimensi pembangunan sesungguhnya akibat penerapan supremasi militer ini. Ini bukan pengalaman khas Indonesia saja, bahwa demokrasi yang dibingkai sebatas definisi terbatas berdasarkan asa keseragaman di bawah otoritas petafsir tunggal yang tak memberi ruang toleransi atas perbedaan secara sehat, begitu buruk akibatnya.

Soeharto tentu menyadari hal ini, dan karena itu melakukan kombinasi tim. Karena itulah militer akhirnya tetap merasa perlu berkolaborasi dengan kalangan sipil tertentu untuk menutupi kelemahan. Di sinilah titik awal hadirnya teknokrat yang dipilih dari kalangan yang berfikiran linear dan para pengagum teori trickle down effect yang mengutamakan pertumbuhan di atas segalanya dengan membuka pintu lebar-lemar kepada modal asing tanpa dispilin yang ditentukan secara imperatif oleh konstitusi.

Di tangan mereka pembangunan adalah pertumbuhan yang sangat ekslusif. Teknokrat menjadi pilihan didasarkan pada pengalaman ketidak-puasan terhadap kalangan politisi sipil. Politisi sipil sudah terlanjur dianggap kedodoran dalam mengelola politik dan ekonomi Negara. Teknokrat dan militer tampaknya mempunyai orientasi yang 
lebih mungkin dipersamakan ketimbang militer-politisi sipil. Asumsi dan kolaborasi ini berlangsung tanpa kritik dan perlawanan yang berarti hingga perubahan peta global memaksa Indonesia berubah dengan faktor pemicu gerakan mahasiswa tahun 1998.

Apa yang berbeda dengan pemerintahan sekarang? Kita mungkin bisa melihat agenda awal Presiden Jokowi mengagendakan pembicaraan pada berbagai forum internasional. "We are waiting for you in Indonesia. We are waiting for your investation", adalah dua kalimat kunci menandai kehadiran Presiden Jokowi di pentas-pentas internasional yang menunjukkan watak kompradoritas.

Dalam waktu yang sangat singkat Cina telah menghubah struktur kebijakan politik dan ekonomi Indonesia dan memastikannya menjadi ketentuan imperatif. Untuk salah satu kasus kehadiran Cina di Indonesia, Yusril Ihza Mahendra mempertanyakan persoalan pembangunan kereta api cepat Bandung-Jakarta. Bahkan, ia mempertanyakan kelayakan Cina disebut sebagai investor. Apakah urgen membangun jalur kereta api cepat yang menghubungkan Bandung-Jakarta sedangkan jalan tol Cipularang, kereta api yang ada sekarang, dan pesawat yang terbang Jakarta-Bandung PP sudah cukup memuaskan.

Biaya pembangunan kereta cepat itu 5 miliar dolar AS (Rp 78 triliun), tidak berasal dari pengalihan subsidi BBM, melainkan setoran equity $25 \%$ konsorsium 4 (empat) BUMN senilai hampir Rp 19 triliun. Sedangkan sisanya (75\%) berasal pinjaman dari Cina kepada 4 BUMN tersebut yang harus dilunasi selama 60 tahun. Anehnya kontraktor pembangunan kereta cepat itu adalah Cina sendiri yang berdasarkan pengalaman di mana-mana di Indonesia, akan sekaligus juga mebawa tenaga kerja dari negaranya. Sekiranya kontraktor itu lalai atau wanprestasi mengerjakan proyek kereta cepat itu, apa yang akan terjadi dengan pinjaman kepada konsorsium 4 BUMN itu?, Tanya Yusril Ihza Mahendra. Baginya tak mustahil Cina akan akuisisi saham keempat konsorsium BUMN tersebut. Maka, Cina dapat menjadi penguasa BUMN.

Pemerintah menunjukkan antipatinya terhadap subsidi sebagai alasan untuk memajukan pembangunan Indonesia. Filosofi itu sangat aneh dianggap oleh dunia internasional. Sebagai perbandingan, Malaysia hingga kini masih melakukan kebijakan subsidi sebesar RM 24.933.000.000 untuk jenis-jenis kebutuhan dasar rakyat, antara lain (a) Liquified petroleum gas, solar dan bensin sebesar RM 10.000.000.000 (40 \%); (b) Bantuan pendidikan RM 7.101.000.000 (28 \%); (c) Bantuan Sosial lainnya RM 2.327.000.000 (9 \%); (d) Subsidi selisih suku bunga dan listrik RM 1.514.000.000 (6 \%); (e) Padi, beras, gula dan tepung RM 2.0131.000.000 (8 \%); (f) Skema stabilisasi minyak sayur RM 828.000.000 (3 \%); (g) Aneka Insentif RM 629.000.000 (2 \%); (h) Lainnya 503.000 .000 (2\%).

Pengaturan sumberdaya dan sektor strategis memerlukan tinjauan radikal, karena Negara mengelola ekonomi agar setiap warga memiliki peluang (equal access) dalam memproduksi dan menikmati hasil dari ekonomi. Sistem ekonomi Indonesia mengatur dengan tegas sumber ekonomi apa saja (SDA dan cabang produksi penting) yang dikuasai oleh Negara, bagaimana cara mengelolanya dan digunakan untuk apa saja seperti kekayaan alam (air, minyak, tambang, laut dan sebagainya), dan cabang produksi penting seperti perbankan dan keungan, transportase, dan lain-lain. 
Kini orang semakin lupa dan tak sadar bahwa untuk kesejahteraan seluruh rakyat system ekonomi Indonesia mestinya wajib menempatkan pentingnya peran-negara yang tidak hanya sekadar ditunjukkan dengan eksistensi BUMN dan BUMD yang di dalamnya Negara menjadi salah satu pelaku eknomi, tetapi juga mengatur strategi dan kebijakannya untuk pengaturan kepemilikan, pengaturan produksi dan konsumsi nasional dengan tujuan akhir kesejahteraan rakyat.

Mestinyalah BUMN dan BUMD menjadi salah satu pilar penting dalam pembangunan ekonomi dan dalam mengelola berbagai sector strategis. Pembangunan BUMN dan BUMD harus menggunakan pendekatan sinergi di antara sesama BUMN dan BUMD sebagai unit usaha yang terintegrasi dengan tanggungjawab BUMN dan BUMD lain, yang semestinya memiliki backward dan forward linkage di antara sesamanya. Misalnya, harus ada strategi terintegrasi antara pengembangan BUMN dan BUMD migas dan tambang dengan BUMN dan BUMD pengelola migas (Pertamina) dan BUMN dan BUMD pengguna hasil tambang (PLN). Begitu juga BUMD perbankan dengan unit-unit pemerintahan yang bekerja pada level ekonomi kerakyatan.

Pada bagian sebelumnya telah dikemukakan bahwa buku The Rise of Ersatz Capitalism in South-East Asia (1988) yang ditulis oleh Kunio Yoshihara menganggap kapitalisme Indonesia yang bersifat ersatzs atau pseudo capitalism perlu dirubah dengan tiga rekomendasi, yakni menanggulangi keterbelakangan teknologi, memperbaiki kualitas intervensi pemerintah, dan menghapus diskriminasi terhadap orang-orang keturunan Cina.

Ketiga faktor itu dianggapnya dapat merombak watak pembangunan yang tidak efisien untuk berubah menjadi kapitalisme yang tak berbeda dengan di Jepang dan dunia Barat pada umumnya. Jalannya ialah sistem sosial dan politik harus dibangun sedemikian rupa agar kapitalisme yang dinamis dapat tumbuh. Rekomendasi Kunio Yoshihara tak sepenuhnya melakukan pemilahan berdasarkan peran keturunan Cina di berbagai Negara di Asia tenggara. Karena pada dasarnya diskriminasi terhadap keturunan Cina di Indonesia malah adalah sebuah penegasan penting atas penguasaan mereka atas ekonomi.

\section{Dominasi Etnis Cina}

Sejak zaman penjajahan Belanda diskriminasi yang terjadi malah dalam bentuk penempatan orang yang berasal dari Timur Asing termasuk keturunan Cina sebagai warga kelas satu. Dampaknya sangat buruk hingga hari ini. Diskriminasi yang sesungguhnya malah akan kelihatan jika memeriksa tidak pada bagian hilir seperti selama ini diteriakkan dengan amat bersemangat oleh kalangan tertentu. Bukankah hasil diskriminasi jika setiap tahun pengumuman nama orang terkaya di Indonesia mutlak didominasi oleh kerutunan Cina?

Dalam dialog yang diselenggarakan oleh Karni llyas melalui program ILC yang dia asuh (13 Januari 2016), Yusril Ihza Mahendra memberi data bahwa 0,2 \% orang Indonesia menguasai $74 \%$ dari keseluruhan tanah melalui konglomerasi, real-estate, pertambangan, perkebunan sawit, HPH dan sebagainya. Ini bom waktu, katanya, apalagi, maaf-maaf kalau memakai bahasa lama, mereka yang 0,2 \% itu non 
primbumi. Karni llyas menimpali, $50 \%$ kekayaan Indonesia hari ini adalah milik $1 \%$ warga negara.

Ekonomi konstitusi wajib ditegakkan

Pilar kewajiban sosial ekonomi pembangunan wajib dengan kehadiran pemerintah untuk pengaturan ekonomi. Di antaranya dengan pelaksaan kewajiban yang dituntut pasal 23 ayat (1) tentang kewajiban mengelola anggaran (APBN dan termasuk APBD) untuk kesejahteraan; pasal 27 ayat (2) tentang hak warganegara atas pekerjaan dan penghidupan yang layak bagi kemanusiaan, tidak justru hanya melihat keniscayaan persaingan di pasaran kerja berbasis persaingan sengit saling mengeliminasi. Juga pasal 28 tentang kewajiban pemenuhan kebutuhan dan pelayanan dasar. Pasal 31 tentang hak mendapatkan pendidikan bagi seluruh warga Negara. Pasal 34 tentang kewajiban menjamin fakir miskin dan anak terkantar untuk mendapatkan kebutuhan dan pelayanan dasar. Pengaturan kepemilikan dan struktur ekonomi, antara lain ditegaskan oleh pasal 33 ayat (1) tentang pengelolaan ekonomi berbasis kebersamaan; pasal 33 ayat (2) tentang penguasaan Negara atas cabang produksi penting; pasal 33 ayat (3) penguasaan dan kepemilikan Negara atas kekayaan alam.

Sistem ekonomi Indonesia perlu dibangun kembali dengan filosofi yang sudah digariskan oleh konstitusi, untuk tujuan mewujudkan kesejahteraan seluruh rakyat. Sistem itu menegaskan asas kebersamaan, hak-hak warganegara atas kebutuhan dan pelayanan dasar, bukan dengan kompetisi. Sektor-sektor penting yang wajib diatur berdasarkan ketentuan imperative konstitusi itu antara lain pangan, pendidikan, kesehatan, transportase, energi, air dan lain-lain.

\section{Globalisasi}

Apa yang oleh Yusril Ihza Mahendra sebagai bom waktu tidak hanya berasal dari buruknya penguasaan minoritas keturunan Cina atas ekonomi. Kerjasama dalam pasar global juga menjadi ladang pembataian yang sistematis. Masyarakat Ekonomi ASEAN (MEA) misalnya, sebagai sebuah bentuk kerjasama ekonomi di antara negara-negara yang tergabung dalam ASEAN adalah keniscayaan integrasi ekonomi regional yang bertalian erat dengan globalisasi. Baik MEA mau pun agenda globalisasi lainnya bukanlah kemauan dan penyikapan atas fakta dinamika semata, melainkan lebih pada keniscayaan interaksi umat manusia yang terjadi secara global.

Banyak fakta menunjukkan optimisme yang berbaur dengan pesimisme secara silih berganti atau bahkan secara simultan di Negara-negara lemah seperti Indonesia. Upaya-upaya berbagai Negara yang bersifat ganda itu berawal pada kesadaran tentang ancaman-ancaman baru yang pasti muncul dengan sifat borderlessness hubungan antar Negara yang mengakibatkan degradasi peran Negara yang menyerah kepada inisiatif-inisiatif orang dan kelompok-kelompok dunia usaha yang bersamasama berusaha menciptakan kebebasan dalam pasar.

Hampir bersamaan terjadi, bahwa pada satu pihak tampak berbagai Negara berusaha melakukan upaya yang mengarah pada gerakan sentrifugal (penyatuan menyeluruh), tetapi pada pihak lain juga melakukan usaha bersifat sertripetal (penyatuan kelompok atau rumpun khas menegasikan interaksi global). Kemenduaan ini tidak pernah berakhir sampai sekarang, dan umumnya optimisme dan pesimisme bukan sesuatu 
yang baru, melainkan watak Negara-negara dunia sejak awal yang lebih diperkuat sejak berakhirnya perang dunia ke II. Mereka yang secara tradisional berada pada wilayah lebih berkuasa dan lebih makmur, bergerak lebih maju dan lebih memastikan keabadian watak pemangsaannya berlindung di bawah aturan-aturan internasional yang mereka inisiasi untuk disetujui oleh semua Negara.

Itulah sebabnya berbagai kawasan di dunia telah lebih dahulu membentuk aliansialiansi spesifik yang menunjukkan kearenaan kawasan mereka sendiri yang lebih berkarakter spesifik dalam menghadapi globalisasi. Jika globalisasi dimaknai sebagai suatu situasi yang mempraktikkan perdagangan bebas, tanpa hambatan tarif (bea cukai) bagi Negara-negara anggotanya, maka segera saja akan terdapat banyak pilihan yang menyenangkan dan mencemaskan sekaligus.

Ada hal-hal yang sangat mendua

Dunia berbicara tentang polarisasi dengan rekomendasi kewajiban memanusiakan tata dunia antara lain dengan dimunculkannya program-program seperti MDCS (Millenium Development Goals) yang berakhir September 2015 yang meskipun tak dapat dipertanggungjawabkan nilai klaim keberhasilannya, serta-merta digantikan dengan model pembangunan berkelanjutan baru yakni Sustainable Development Goals (SDGs) yang telah disahkan dan disepakati bersama oleh negara-negara anggota Perserikatan Bangsa-Bangsa (PBB) untuk menjadi agenda pembangunan internasional selama lima belas tahun kedepan (2015-2030).

Baik MDGs maupun SDGs sangat mulia pada statemen dan publikasinya, namun secara substantif sangat tidak mungkin dilaksanakan karena struktur tata dunia yang tidak mungkin adil. PBB sudah membuktikan berulangkali kegagalannya sejak dibentuk pasca perang dunia II. Indonesia mencatatkan protesnya yang keras, baik melalui pembentukan aliansi strategis berbau sentimen di antara Negara-negara eks jajahan dan miskin di dua kawasan yang dinamai konferensi Asia-Afrika di Bandung, maupun melalui upaya-upaya diplomasi seperti yang terlihat sangat jelas dalam kecaman pidato-pidato para tokoh Indonesia di forum PBB itu (Soetan Sjahrir, Soekarno dan lain-lain) serta aksi keluar dari keanggotaan PBB meskipun Indonesia kembali bergabung.

Politik Penyingkiran

Kita masih ingat penerapan dwi-fungsi ABRI zaman Orde Baru di bawah kepemimpinan Soeharto. Sebetulnya model itu adalah sesuatu yang cukup menyimpang dari blue print yang ada dalam pikiran para tokoh utama pencetus seperti Jenderal AH Nasution. Sebagaimana diketahui, pada akhirnya Jenderal $A H$ Nasution pun, bersama tokoh militer berpengaruh lainnya, diposisikan kurang lebih sebagai "musuh" pembangunan oleh rezim berkuasa. Tetapi rezim Orde Baru melakukan tidak sebatas eliminasi sistematis terhadap tokoh-tokoh militer berpengaruh.

Lebih luas dari itu, berlangsungnya mekanisme penyingkiran politik, menurut Guillermo O'Donnel (Modernization and Bureaucratic-Authorianism, Berkeley: Institute of international Studies, University of California, 1979) menyangkut tindakan pemerintah yang ditujukan untuk menyingkirkan sektor populer kota yang telah aktif 
sebelumnya dari area politik nasional. Dalam kebijakan birokrasi pemerintahan berlangsung pola bipolar and segmentary process (proses pemilahan dan penganaktirian). Penyingkiran bermakna pemerintah secara konsisten menolak untuk memenuhi tuntutan-tuntutan politik yang dibuat oleh para pimpinan sektor ini. la juga berarti penghalangan akses sektor ini beserta pimpinannya terhadap posisi dalam kekuasaan politik yang memungkinkan mereka mempengaruhi secara langsung keputusan bagi kebijaksanaan nasional. Menyingkirkan politik dapat dilaksanakan dengan kekerasan secara langsung dan/atau dengan menutup saluran akses politik melalui pemilu.... menyingkirkan para aktor politik melibatkan suatu keputusan yang disengaja untuk mengurangi jumlah orang yang memiliki pengaruh penting dalam menentukan apa yang terjadi pada level kepolitikan nasional.

Dalam penerapan kebijakan bipolar and segmentary process pemerintah tidak hanya mengidentifikasi dan menghukum sesiapa yang dianggap musuh pembangunan sembari memberi reward kepada kelompok-kelompok yang memiliki potensi dukungan. Meskipun partai politik menjadi objek terpenting mekanisme penyingkiran politik Orde Baru, tetapi dampaknya begitu luas. Karena heterogenitas sekaligus juga dipertajam oleh sekat-sekat ideologis yang diciptakan dan semua itu dimaknai pembangunan.

Sesiapa yang tidak memiliki keseragaman dianggap musuh pembangunan dan perlakuan terhadapnya cukup tersedia di bawah tafsir hukum yang ditundukkan di bawah kepentingan penguasa belaka. Menurut Mochtar Mas'oed (1989) sikap antiideologis ini, dibarengi dengan munculnya sikap pragmatisme Orde Baru untuk lebih memusatkan perhatian pada perbaikan dan pembangunan ekonomi, disadari atan tidak telah menumbuhkan ideologi baru: ideologi pembangunan/modernisasi.

Barangali wajiblah bertanya, mengapa begitu marak kemunculan kelompok-kelompok radikal yang tak jarang diikuti dengan tindakan-tindakan repressif penghilangan nyawa orang di Indonesia? Apa yang mereka butuhkan jika bukan keadilan? Dengan sederhana memang seseorang dapat berkata "sesiapa yang melawan dihadapkan kepada hukum Negara, dan segera kita tingkatkan kewenangan alat Negara untuk melakukan tindakan sekeras mungkin untuk membungkam mereka semua". Ini disharmoni nasional, yang akarnya ada pada takaran keadilan. Tidak tertutup kemungkinan proxy war melanda Indonesia, agar sesama anak bangsa saling menghancurkan. Negarawan perlu hadir di sini.

\section{Penutup}

Brutalitas kapitalisme di Indonesia sudah menunjukkan keganasannya. Terjadi ketidakmerataan karena meskipun pertumbuhan cukup tinggi, namun terus diikuti oleh kesenjangan. Hampir $40 \%$ rakyat masih tergolong miskin dan mendekati miskin. Fakta yang menunjukkan masih rendahnya tingkat pendidikan dan kesempatan untuk mengecap pendidikan tinggi yang pada gilirannya memunculkan fakta lain tenaga kerja didominasi oleh lulusan pendidikan SD yang tak bersaing, menunjukkan absennya negara.

PDB per kapita dan tingkat pendidikan berada pada posisi degradatif, di bawah posisi Cina dan disusul oleh Vietnam. Brutalitas kapitalisme di Indonesia juga telah 
melahirkan fenomena sensitif, yakni terjadi kesenjangan antara kawasan Barat dan Timur. Dalam banyak keluhan yang tak usai, hingga kini tidak ditemukan mengapa Negara tidak berhasil mengoptimalkan SDA sebagai modal pembangunan yang memakmurkan seluruh rakyat.

Kesalah-fahaman dalam kebijakan penciptaan lapangan kerja yang hampir tanpa arah, kalau bukan berlangsung dengan sendirinya, juga wajib dikoreksi. Asumsi yang kini dikembangkan ialah bahwa warga negara wajib berkompetisi, jika tak mampu yang terimamkekalahan. Iklim ini tidak dikehendaki oleh konstitusi. Brutalitas kapitalisme juga menyebabkan pertanian berkurang secata terus-menerus, bergeser ke sektor jasa (informal) tanpa jawaban yang pasti untuk merevitalisasi sehingga mampu menjawab ketahanan pangan.

Pada pembangunan setiap sektor keterpilihan kebijakan tidak memberi prioritas pada padat karya, dan akibatnya pertanian dan pengolahan tumbuh sangat rendah. Tidak ada rangsangan produktif pada sektor pertanian. Akibatnya Indonesia menjadi importir bahan pangan besar dunia. Nilai impor sangat besar dan tumbuh tinggi terusmenerus. Komposisi impor juga didominasi oleh bahan baku yang menyebabkan ketergantungan industri pada bahan impor. Jika diamati dengan cermat, ada resiko fiskal dan keuangan negara disebabkan peningkatan utang luar negeri yang tidak diimbangi oleh ekspor. Tidak salah berutang, tetapi utang pun memiliki kualitas.

Terakhir, peran negara pada sektor strategis yang terus-menerus berkurang. Ini adalah sebuah trend yang bertentangan dengan trend dunia. Di banyak negara minyak adalah dominasi National Oil Companies, seperti Iran dengan National laranian Oil Company, Saudi Arabia (Saudi Arabian Oil Company), Qatar (Qatar General Petroleum Corporation), Venezuela (Petroleos Venezuela S.A), Iraq (Ira National Oil Company), Kuwait (Kuwait Petroleum Company), begitu juga Negieria, Libya, Algeria, China, Rusia, Mexico, Rusia, Angola, Oman, Francis, Amerika dan lain-lain.

Shohibul Anshor Siregar

Naskah ini pertamakali diterbitkan oleh Harian Waspada Medan, 25 Januari 2016 dan 1 Februari 2016 